UDC 1:005.35

LBC 87.524.85

\title{
PROMOTION OF SOCIALLY RESPONSIBLE BEHAVIOR PATTERNS AS AN ELEMENT OF SOCIAL RESPONSIBILITY INSTITUTIONALIZATION ${ }^{1}$
}

\author{
Nina A. Kalashnikova \\ Volgograd State University, Volgograd, Russian Federation
}

\begin{abstract}
The study of moral and ethical grounds for socially responsible behavior of representatives of business community and NGOs in Volgograd showed that the predominant importance in the implementation of socially responsible activities for the designated category of citizens have ethically colored individual motives. However, due to these motives, informal initiative cannot completely replace the institutionally organized (systemic) forms of social responsibility, the problem of the lack of which in the region is quite acute.

Public dissemination of samples of socially responsible behavior in order to consolidate them in the mass consciousness and transform them into sustainable practices, a certain kind of propaganda (in the narrow sense of the word), will create a systemically organized, institutionalized environment for the implementation of socially responsible behavior. Business structures will be involved in the described environment in appropriate cases. In addition, the institutionalization of social responsibility, through standardization, will become a "resource-saving technology" for organizations implementing a variety of socially oriented programs, allowing to avoid spending extra effort on the "invention" of individual forms of implementation of socially responsible behavior, and distracting from the form, focus on the content. In the future, the institutionalization of social responsibility will help to create the basis for constructive dialogue between government, business and civil society on the basis of increasing self-reflexivity of each of the subjects of social interaction, understanding fully its active role in respect of social and economic change and responsibility for chosen strategy and its implications. Promotion of models of socially responsible behavior, based primarily on moral and ethical grounds, will contribute to the gradual development and improvement of public relations in the region. Media and social networks serve as channels and platforms for broadcasting samples of socially responsible behavior. The means of broadcasting include advertising, socially significant actions of various scales. The transformation of social responsibility into a trend will change the thinking of both the initiators of socially oriented activities in the face of the heads of organizations and its addressees.

Key words: socially responsible behavior, institutionalization of social responsibility, promotion of social responsibility, advertising, critical thinking, political culture, business community.
\end{abstract}

УДК 1:005.35

ББК 87.524 .85

\section{ПРОДВИЖЕНИЕ ОБРАЗЦОВ СОЦИАЛЬНО ОТВЕТСТВЕННОГО ПОВЕДЕНИЯ КАК ЭЛЕМЕНТ ИНСТИТУАЛИЗАЦИИ СОЦИАЛЬНОЙ ОТВЕТСТВЕННОСТИ ${ }^{1}$}

\author{
Нина Александровна Калашникова \\ Волгоградский государственный университет, г. Волгоград, Российская Федерация
}

\footnotetext{
Аннотация. Исследование морально-этических оснований социально ответственного поведения представителей бизнес-сообщества и НКО в г. Волгограде показало, что преобладающее значение в осуществлении социально ответственной деятельности для обозначенной категории граждан имеют этически окрашенные индивидуальные мотивы. Однако обусловленная указанными мотивами неформальная инициатива не может полностью заменить институционально организованных (системных) форм социальной ответственности, проблема отсутствия которых в регионе стоит достаточно остро.
} 
Публичное распространение образцов социально ответственного поведения с целью их закрепления в массовом сознании и преобразования в устойчивые практики, определенного рода пропаганда (в узком смысле слова), позволит создать системно организованную, институционально оформленную среду для реализации социально ответственного поведения. В описанную среду с необходимостью будут вовлечены бизнес-структуры. Кроме того, институализация социальной ответственности благодаря стандартизации станет «ресурсосберегающей технологией» для организаций, реализующих разнообразные социально ориентированные программы, позволяя не затрачивать лишних усилий на «изобретение» индивидуальных форм осуществления социально ответственного поведения и, отвлекаясь от формы, сосредоточиться на содержании. В перспективе институализация социальной ответственности поможет создать основу для конструктивного диалога между властью, бизнесом и гражданским обществом на основе повышения саморефлексивности каждого из перечисленных субъектов социального взаимодействия, осознания в полной мере своей активной роли в отношении социально-экономических преобразований и ответственности за выбранную стратегию действий и ее последствия. Продвижение образцов социально ответственного поведения, опирающееся прежде всего на морально-этические основания, будет способствовать постепенному развитию и оздоровлению общественных отношений в регионе. Каналами и площадками для трансляции образцов социально ответственного поведения выступают СМИ, социальные сети. К числу средств трансляции можно отнести рекламу, социально значимые акции различного масштаба. Превращение социальной ответственности в тренд позволит изменить мышление как инициаторов социально ориентированной деятельности в лице руководителей организаций, так и ее адресатов.

Ключевые слова: социально ответственное поведение, институализация социальной ответственности, пропаганда социальной ответственности, реклама, критическое мышление, политическая культура, бизнессообщество.

Идея жесткой конкуренции за материальные блага и ресурсы как системообразующий элемент мировоззрения, закономерно вытекающая из приоритетов рыночной экономики, в условиях современной российской действительности показывает себя как источник социальных конфликтов и противоречий. В связи с этим все большее число отечественных исследователей останавливает свое внимание на феномене социально ответственного поведения как факторе социальной саморегуляции, не акцентируясь, за редким исключением, ни на его морально-этических основаниях, ни на процессе его институализации. В то же время выявление морально-нравственных установок, побуждающих представителей коммерческих и некоммерческих организаций к социально ответственному поведению, наряду с исследованием перспектив институализации последнего, представляется актуальным в контексте инновационного развития региона в целом и г. Волгограда в частности.

В рамках исследования морально-этических оснований социальной ответственности в современном российском обществе (на примере организаций г. Волгограда) на эмпирическом уровне с применением методов глубинного интервью и сетевого тематического анализа мнений экспертов была установлена взаимосвязь между качеством общественного взаимодействия и продвижением принципов социальной ответственности. Продвижение, как можно понять из ответов экспертов, в роли которых выступили руководители коммерческих и некоммерческих организаций г. Волгограда, включает в себя пропаганду социально ответственного поведения и акции, при помощи которых субъекты социальной ответственности смогут решить важные для общества проблемы (см. рисунок).

Условием повсеместного вхождения социально ответственного поведения в практику российских (и региональных) организаций, как отмечают некоторые респонденты, является то, что «это должно стать модно. Мы должны воспитать наших детей. И какой пример мы им показываем. Если мы выбрасываем мусор и это видят дети. Или мы идем и помогаем и говорим, почему мы помогаем. Нет, здесь только пропаганда, в хорошем смысле, без экстремистского окраса. Ну и поощрение со стороны бизнес сообщества. Есть хорошие дела, которые надо обязательно поощрить: составить реестр, общедоступный на сайте в интернете. Указать компанию, указать адрес и что это. Другие подумают, мой конкурент делает это. Так мы привлечем сообщество, показывая друг другу пример» (респондент № 13). 


\section{ОСНОВАНИЯ СОЦИАЛЬНОЙ ОТВЕТСТВЕННОСТИ}

Интересной в данном контексте представляется идея, связанная с созданием общедоступного интернет-ресурса, на котором был бы размещен реестр «хороших дел» организаций г. Волгограда, что само по себе могло бы послужить для обозначенных организаций формой поощрения их деятельности. Такая инициатива могла бы стать основой для продвижения образцов социально ответственного поведения в г. Волгограде, выработки определенных стандартов социально ответственной деятельности, ее общей стратегии, в том числе и посредством социальных сетей.

Пропаганда социально ответственного поведения также включает в себя идеи, связанные с пониманием социальной ответственности как нормы и как тренда, с ценностью для бизнеса просветительских встреч, публичным характером социальной ответственности, лояльностью к бренду организации. Акции, в свою очередь, ассоциируются с социально значимыми мероприятиями и их информационной поддержкой, а в негативном смысле с использованием некоторыми депутатами социальных акций в целях саморекламы.

К социально значимым акциям, нацеленным на распространение образцов социально ответственного поведения, респонденты, например, относят решение некоторых локальных экологических проблем: установку специальных контейнеров по раздельному сбору мусора, - «вывоз, уход за ними - это не коммерческая история, не приносит никакого дохода, но мы это поддерживаем как образовательный, социально значимый проект. Плюс деткам лекции в школах проводим, субботники...» (респондент № 7), а также организацию праздников и конкурсов для детей.

Общим мотивом для социально ответственной деятельности представителей бизнессообщества и НКО г. Волгограда выступает

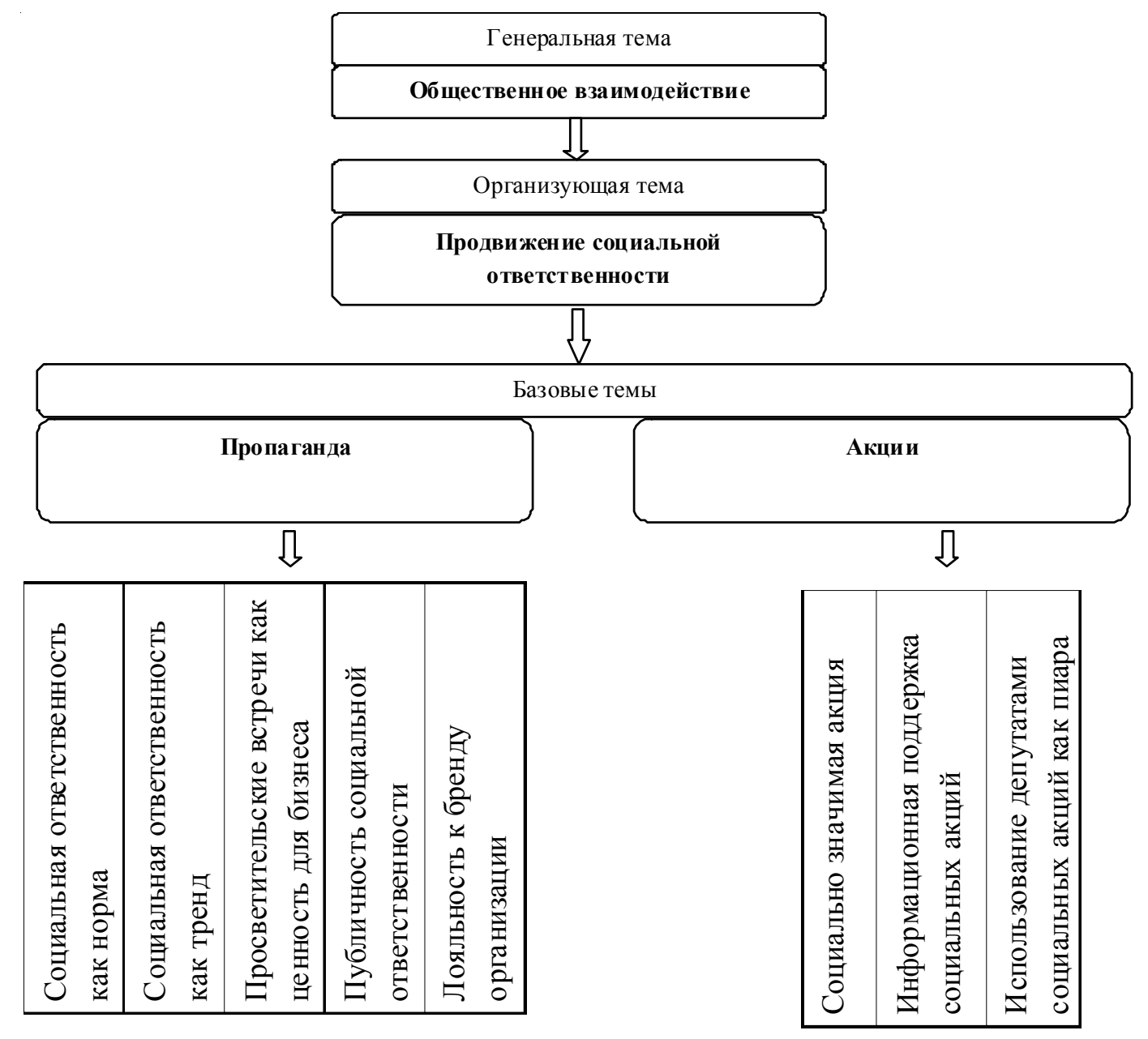

Результаты СТА по организующей теме «Продвижение социальной ответственности» 
система индивидуальных нравственно-этических предпочтений субъектов данной деятельности. Это характерно для г. Волгограда. В этих условиях тиражирование образцов социально ответственного поведения посредством «неэкстремистской пропаганды» и в определенных случаях социальной рекламы позволит создать и усилить эффект, который социальная ответственность оказывает на общество. «Современные рыночные системы поощряют тот бизнес, который не только этично достигает основную цель - получение прибыли, но и вкладывает средства в реализацию социальных проектов, ориентируется на создание общественных ценностей. Активное распространение новой идеологии ведения бизнеса во многом обусловлено осознанием в предпринимательской среде простой истины: уровень экономического развития является в значительной мере производным от степени решения социальных проблем в данном обществе и состояния социальной сферы в целом» [Савичева 2011, 17].

Понимание представителями бизнессообщества того факта, что социально ответственное поведение - это необходимое для самосохранения направление деятельности в условиях экономической и политической нестабильности, должно существенно повысить уровень социальной ответственности бизнеса. «Мировой опыт и результаты социологических исследований регулярно показывают, что бизнес, который ведет себя социально ответственно, имеет большие шансы на выживание в условиях кризиса» [Виттенберг 2017, 106].

Что касается рассмотрения путей институализации социальной ответственности с учетом политических процессов в регионе, то согласно одной из трактовок необходимое условие - это «повышение степени субъектности», то есть осознание бизнес-сообществом себя в качестве полноценного социального субъекта, отличающегося активной позицией, преобразовательной деятельностью по отношению к окружающей социальной реальности и несущего ответственность за свои действия. Достаточным условием выступает здесь правильно организованная институциональная среда, в которой развивается бизнес [Сукиасян, Евстифеева 2013, 221].
К числу имманентных факторов, детерминирующих процесс институализации социальной ответственности, относят и политическую культуру. Функция последней заключается в стабилизации политических процессов, уменьшении политической неопределенности. Прослеживается связь между особенностями политической культуры и специфическими чертами конкретной модели социальной ответственности применительно к российской среде: «Основополагающими чертами современной российской политической культуры являются партикуляризм и аскриптивность. $<\ldots>$. Как результат, значительный диапазон накопившихся социокультурных изменений, которые не соответствуют уровню институционального развития... < ..> ...Транзитарный тип политической культуры обусловливает устойчиво-незавершенный характер институционализации социальной ответственности бизнеса» [Сукиасян, Евстифеева 2015, 92].

Бесспорно, важнейшая роль в создании и поддержании имиджа социально ответственного бизнеса принадлежит рекламе и СМИ, которые являются одним из эффективных способов приобщения широких масс граждан к содержанию различных социально ориентированных проектов и акций и тем самым помогают тиражировать образцы социально ответственного поведения.

«Как правило, при изучении роли рекламы в формировании и продвижении имиджа социально ответственного бизнеса рассматривается социальная реклама, которая в отличие от рекламы коммерческой выходит за рамки экономических задач бизнеса» [Морозова и др. 2013, 30]. Социальная реклама «высвечивает» те социальные проблемы, которые могут решить социально ответственные субъекты бизнеса и НКО, кроме того, она может демонстрировать обществу образцы таких решений. Тем не менее, в продвижении имиджа социально ответственного поведения не стоит ограничиваться только социальной рекламой.

Реклама как структурный элемент информационно-коммуникативного пространства в современной социальной среде способна выполнять применительно к массовому сознанию не только привычную манипулятивную, но и конструктивную воспитательную функ- 
цию, транслировать и тиражировать успешные примеры социально ответственной деятельности, служить инструментом «пропаганды социально ответственного образа жизни» с учетом двунаправленного характера подобного взаимодействия, поскольку реклама, как и любой феномен культуры, будучи когда-то создана человеком, впоследствии сама непосредственно влияет на формирование следующих поколений людей.

При этом деструктивному воздействию рекламы, в процессе которого информационно-психологическому давлению через социальные сети, средства массовой информации и т. д. подвергается как индивидуальное, так и массовое общественное сознание с целью побудить субъектов социального действия открыто или латентно действовать вопреки собственным интересам, реализуя интересы тех социальных групп или организаций, которые осуществляют данные воздействия, потребителям рекламы нужно быть готовым противопоставить умения и навыки критического мышления. Последние необходимо развивать, поскольку их образовательная ценность в современном обществе равна «умению читать и писать» [Halpern 2003, 10].

К упомянутым интеллектуальным умениям и навыкам относятся: 1) связанные с восприятием и обработкой информации: оценка степени достоверности источников информации, поиск релевантной информации и ее последующий анализ; 2) логические навыки, используемые в коммуникации и принятии решений: анализ и оценка убедительности аргументов и логической корректности выводов, практика вопросно-ответных процедур с целью уточнения информации и выявления возможных ошибок, четкость и ясность в изложении собственной точки зрения и адекватный выбор языковых средств, принятие решений на рациональной основе и обоснование своего выбора; 3 ) связанные с преодолением инерции мышления: умение воспринимать альтернативную позицию по рассматриваемой проблеме, учитывать различные подходы к ее анализу.

Продуктивным для продвижения социальной ответственности также может оказаться применение навыков критического мышления, относимых к аффективным: уме- ние разграничивать эгоцентризм и социоцентризм как установки и мотивы деятельности; умение выявлять и осознавать связь убеждений и эмоций; готовность сдерживать торопливые суждения и скоропалительные выводы, выносимые под влиянием эмоций и настроений; умение справляться со страхом неизвестного; способность проявлять скрупулезность и настойчивость в решении интеллектуальных задач и преодолении интеллектуальных трудностей [Paul et al. 1995].

Критическое мышление повышает сопротивляемость манипуляциям за счет высокого уровня осознанности интеллектуальных действий и систематически применяемой рефлексии; способности к самостоятельному осмыслению и отбору информации; преодолению стереотипов мышления, в том числе конформизма как личностной установки. Массовое овладение агентов социальных действий умениями и навыками критического мышления позволит существенно уменьшить воздействие деструктивных манипулятивных практик, формирующих искаженную картину социальной реальности, что даст возможность прогнозировать социальные риски и поддерживать стабильное функционирование социальной системы.

Таким образом, критическое восприятие информации является необходимым условием выхода за пределы круговорота манипулятивных воздействий, поскольку обеспечивает повышение общего уровня критичности общественного и индивидуального сознания и логической культуры мышления у социальных субъектов на массовом уровне. Благодаря критическому анализу информации возможно говорить о свободе выбора и мышления и формировании благоприятного социального климата для распространения и усвоения образцов социально ответственного поведения.

Реализация образовательного и воспитательного потенциала рекламы, следовательно, невозможна без развитого критического мышления, которое повышает степень информационной безопасности субъектов социальных отношений, поскольку помогает самостоятельно анализировать информацию, прогнозировать развитие событий, делать выводы и в сжатые сроки принимать решения. 
Продвижение образцов социально ответственного поведения компаний посредством СМИ, рекламы, социальных сетей должно быть нацелено не только на внедрение концепта «социально ответственное поведение» в массовое сознание в качестве нормы в рамках постепенной институализации обозначенного феномена, но и на изменение способа мышления как инициаторов социально ориентированных программ, так и их адресатов. Данные изменения будут выражаться в усилении саморефлексивности субъектов социально ответственного поведения, осознании своей активной гражданской позиции и готовности к диалогу с властью и обществом.

\section{ПРИМЕЧАНИЕ}

${ }^{1}$ Работа выполнена при финансовой поддержке РФФИ и Администрации Волгоградской области, проект № 18-411-340013 «Морально-этические основания социальной ответственности в современном российском обществе (на примере организаций г. Волгограда)».

The study was conducted with the financial support of RFBR, project no. 18-411-340013 and Administration of the Volgograd region "Moral and ethic grounds of social responsibility in modern Russian society (illustrated by an example of organizations of Volgograd)".

\section{СПИСОК ЛИТЕРАТУРЫ}

Виттенберг 2017 - Виттенберг Е.Я. Социальная ответственность российского бизнеса в условиях кризиса // Вестник института социологии. 2017. Т. 8, № 1. С. 77-113.

Морозова и др. 2013 - Морозова И.А., Гущинна Е.Г., Витальева Е.М., Трошин А.В. Роль и место концепта рекламы в формировании имиджа социально ответственного бизнеса в России // European Social Science Journal. 2013. № 2 (30). C. 24-31.

Савичева 2011 - Савичева Е.Ю. К вопросу о дефиниции категории «социальная ответственность бизнеса» // Российское предпринимательство. 2011. Т. 12, № 8. С. 17-22.

Сукиасян, Евстифеева 2013 - Сукиасян А.Х., Евстифеева О.Г. Механизм институционализации социальной ответственности бизнеса // Вестник
Адыгейского государственного университета. Серия 1, Регионоведение: философия, история, социология, юриспруденция, политология, культурология. 2013. № 1 (113). С. 220-225.

Сукиасян, Евстифеева 2015-Сукиасян А.Х., Евстифеева О.Г. Политическая культура как имманентный механизм институционализации социальной ответственности бизнес-сообщества // Известия Саратовского университета. Новая серия. Серия: Социология. Политология. 2015. T. 15, № 4. C. 92-97.

Paul et al. 1995 -Paul R., Binker A., Martin D., Adamson $K$. Critical Thinking Handbook. Santa Rosa: Foundation for Critical Thinking, 1995.

Halpern 2003 -Halpern D. Thought and Knowledge: An Introduction to Critical Thinking. New Jersey: Lawrence Erlbaum Associates, Inc., Publishers, 2003.

\section{REFERENCES}

Wittenberg E.Y., 2017. Social responsibility of Russian business in a crisis. Bulletin of the Institute of Sociology, no. 1, vol. 8, pp. 77-113.

Morozova I.A., Gushchina E.G., Vitalieva E.M., Troshin A.V., 2013. The role and place of the advertising concept in shaping the image of socially responsible business in Russia. European Social Science Journal, no. 2 (30), pp. 24-31.

Savicheva E.Y., 2011. To the question of the definition of the category "social responsibility of business". Russian Entrepreneurship, vol. 12, no. 8, pp. 17-22.

Sukiasyan A.K., Evstifeeva O.G., 2013. The mechanism of institutionalization of social responsibility of business. Bulletin of the Adygea State University. Series 1, Regional studies: philosophy, history, sociology, jurisprudence, political science, cultural science, no. 1 (113), pp. 220-225.

Sukiasyan A.K., Evstifeeva O.G., 2015. Political culture as an immanent mechanism for institutionalizing the social responsibility of the business community. News of Saratov University. New series. Series: Sociology. Political science, vol. 15 , no. 4, pp. 92-97.

Paul R., Binker A., Martin D., Adamson K., 1995. Critical Thinking Handbook. Santa Rosa, Foundation for Critical Thinking.

Halpern D., 2003. Thought and Knowledge: An Introduction to Critical Thinking. New Jersey, Lawrence Erlbaum Associates, Inc., Publishers. 


\section{ОСНОВАНИЯ СОЦИАЛЬНОЙ ОТВЕТСТВЕННОСТИ}

\section{Information about the Author}

Nina A. Kalashnikova, Candidate of Sciences (Philosophy), Associate Professor, Department of Philisophy, Volgograd State University, Prosp. Universitetsky, 100, 400062 Volgograd, Russian Federation, nika82@yandex.ru, socphil@volsu.ru, https://orcid.org/0000-0002-4072-0390

\section{Информация об авторе}

Нина Александровна Калашникова, кандидат философских наук, доцент кафедры философии, Волгоградский государственный университет, просп. Университетский, 100, 400062 г. Волгоград, Российская Федерация, nika82@yandex.ru, socphil@volsu.ru, https://orcid.org/0000-0002-4072-0390 